\title{
Mitología y emblemática en Milagros de Nuestra Señora de la Fuencisla (1615), de Jerónimo de Alcalá Yáñez
}

\author{
Mythology and the Emblem Tradition \\ in Jerónimo de Alcalá Yáñez's \\ Milagros de Nuestra Señora de la Fuencisla (1615)
}

\author{
Miguel Donoso Rodríguez \\ Universidad de los Andes (Chile)
}

\section{RESUMEN}

Los emblemas, enigmas y jeroglíficos fueron muy populares en la cultura del Siglo de Oro. La literatura da buena muestra de ello, tal como se puede apreciar en las composiciones literarias que concursaron en los certámenes poéticos que se celebraron con motivo de la entronización de la imagen de la Virgen de la Fuencisla en su nuevo santuario, en Segovia, acontecimiento ocurrido en 1613 y descrito en el libro Milagros de Nuestra Señora de la Fuencisla (1615), del doctor Jerónimo de Alcalá Yáñez, obra que pertenece al género de las relaciones de sucesos, tan populares en el siglo XVII español. En este artículo se estudian algunos jeroglíficos y enigmas descritos en dicho texto, en los cuales se puede apreciar cómo estas composiciones literarias no solo se nutren de la Biblia y del Evangelio, sino también de la emblemática y del mundo mitológico.

Palabras Clave: Literatura del Siglo de Oro, Relaciones de sucesos, Literatura mariana, Emblemática y Mitología, Jerónimo de Alcalá Yáñez, Milagros de Nuestra Señora de la Fuencisla.

\section{ABSTRACT}

The emblems, enigmas and hieroglyphics were very popular in the Golden Age culture. Literature is a good example of this, as it can be seen in the literary works that took part in the poetry competitions held on the occasion of the enthronement of the Virgen de la Fuencisla's image in her new shrine in Segovia, an event that took place in 1613 and that is described in the work Milagros de Nuestra Señora de la Fuencisla (1615), by Dr. Jerónimo de Alcalá Yáñez, which belongs to the genre of events relations, so popular in the Spanish seventeenth century. In this article, we study some hieroglyphs and enigmas included in that work, in which we can see how these literary compositions are not only nourished by the Bible and the Gospel, but also by the Emblem Tradition and the mythological world.

Key words: Golden Age Literature, Event Relations, Emblem Tradition and Mythology, Marian Literature, Jerónimo de Alcalá Yáñez, Milagros de Nuestra Señora de la Fuencisla. 
El médico segoviano Jerónimo de Alcalá Yáñez escribió tres obras, la más famosa de las cuales es su novela picaresca Alonso, mozo de muchos amos, también conocida como El donado hablador. Publicada en dos partes en 1624 y 1626, esta obra es un buen ejemplo del derrotero moralizador que siguieron algunos epígonos del género. En cambio, mucho menos conocida es la primera obra que publicó el doctor Alcalá, titulada Milagros de Nuestra Señora de la Fuencisla, grandezas de su nuevo templo y fiestas que en su translación se hicieron por la ciudad de Segovia, de quien es patrona, año de 1613 (Salamanca, en la imprenta de Antonia Ramírez viuda, 1615), escrita por encargo del Ayuntamiento de Segovia. Libro de carácter devoto y mariano, dotado de una estructura de tipo misceláneo, está dedicado a la ciudad de Segovia y su patrona, la Virgen de la Fuencisla, y constituye un relato pormenorizado de las fiestas que se hicieron en la ciudad con motivo del traslado de la imagen de la Virgen desde la iglesia catedral a su nuevo santuario, donde fue emplazada definitivamente el día 23 de septiembre de 1613. El autor, que conocía ya la existencia de otra relación sobre estas fiestas publicada por Jorge Báez en 1614, omite ocuparse en tópicas alabanzas de la ciudad de Segovia y de sus gentes y prefiere centrarse en otros aspectos:

\begin{abstract}
Pareciome cosa acertada dejarlas, como cosas ya sabidas y no muy importantes a mi intento. El cual solo es hacer una breve relación de las fiestas que esta ciudad hizo a la Translación de la devotísima imagen de Nuestra Señora de la Fuencisla a su nuevo templo, el año pasado de mil y seiscientos y trece, donde juntamente será fuerza tratar de la antigüedad desta imagen, de algunos de sus milagros y de la devoción continuada que siempre ha habido con ella hasta en nuestros tiempos $(\text { Prólogo })^{1}$.
\end{abstract}

La obra está estructurada en dos partes bien diferenciadas. La primera, titulada Tratado de los Milagros de Nuestra Señora de la Fuencisla, comprende los capítulos 1 al 10. En los cuatro primeros capítulos de esta parte el autor hace un recorrido por la historia de las imágenes de la Virgen en la primitiva Iglesia y en especial de la imagen de la Fuencisla, probando su antigüedad y refiriéndose a los avatares que sufrió durante la época de la dominación árabe (según la tradición, la imagen fue escondida bajo tierra por don Sácaro a comienzos del siglo VIII, cuando entraron los musulmanes en Segovia, y luego desenterrada durante la Reconquista, en la época de Alfonso VIII, siendo colocada en la fachada de la catedral). Los capítulos 5 al 7 los dedica el autor a transcribir los milagros que motivan el título de la obra, atribuidos a la intercesión de la Virgen de la Fuencisla, resaltando especialmente el de la judía Ester, ocurrido hacia el año 1237. Culpada de un inexistente adulterio, esta mujer fue condenada a ser despeñada, pero en el instante del cumplimiento de la sentencia, al invocar el auxilio de la Virgen, María obró el milagro de

\footnotetext{
${ }^{1}$ Cito por la editio princeps de 1615 (Alcalá Yáñez, 1615), cuyo texto crítico estoy preparando para su publicación.
} 
conducirla sana y salva hasta el suelo. El milagro gozó de cierta fama en la literatura posterior, especialmente religiosa, como lo prueba su aparición en las Cantigas de Alfonso X El Sabio. Alcalá Yáñez reprodujo este relato en la segunda parte del Alonso y también en su tercera obra, Verdades para la vida cristiana $(1632)^{2}$; destacan asimismo otros milagros que nuestro autor, en su calidad de médico, tuvo oportunidad de comprobar en persona. Finalmente (capítulos 8-10), este primer tratado incluye el relato de la construcción del nuevo santuario, fruto del trabajo piadoso y las limosnas de todos los estamentos de la sociedad segoviana, y la preparación de los festejos por la translación de la imagen a su nueva ermita, que constituirán el núcleo de la segunda parte.

Dicha segunda parte, en la que me voy a centrar en este trabajo, lleva por título De las grandiosas fiestas que esta noble ciudad de Segovia celebró en la traslación de la imagen de Nuestra Señora de la Fuencisla a su nuevo templo, este año de 1613, a los doce de septiembre, y comprende los capítulos 11 al 34. Estos capítulos constituyen el núcleo de la obra, y a lo largo de ellos el autor describe detalladamente las fiestas y festejos con que se celebró la referida translación, alabando calurosamente y describiendo con mucho colorido el ambiente vivido en la ciudad con motivo de estas fiestas, que se iniciaron el jueves 12 y culminaron el lunes 23 de septiembre, día de la instalación definitiva de la imagen en su nuevo santuario. Doce días de fiestas que el autor narra pormenorizadamente, relatando cómo las autoridades civiles, presididas por el rey Felipe III y su familia, y los distintos estamentos de la ciudad (nobleza y clero, profesiones liberales, mercaderes, oficiales y artesanos), participaron en los actos: se suceden representaciones de comedias y entremeses, bailes, corridas de toros, rejoneos y juegos de cañas, cabalgatas, fuegos artificiales y luminarias; cada día se repiten las coloridas procesiones de las órdenes religiosas masculinas a la catedral a celebrar misa; también da cuenta de los certámenes literarios que se celebraron, en los que participó como jurado el poeta segoviano Alonso de Ledesma y compitió el propio autor; asimismo, refiere las procesiones de carros alegóricos con motivos bíblicos, etc. Entre el relato de unas y otras actividades el autor va intercalando composiciones poéticas — romances y villancicos- que Ledesma dedicó a la Virgen. Para finalizar, se describe el nuevo santuario donde quedó instalada la imagen (capítulo 34).

Tan variopinto material podría generar algunas dudas respecto del género al que pertenece nuestra obra. Es claro que su carácter es devoto y mariano, pero también lo es descriptivo y misceláneo, por la variedad de fuentes que utiliza (milagros, leyendas y tradiciones; fiestas, juegos y diversiones; cróni-

\footnotetext{
${ }^{2}$ Véase, para el tema del milagro de la judía Ester, el relato contenido en la novela Alonso, mozo de muchos amos, de Jerónimo de Alcalá Yáñez (2005: 665-670 y n. 886). Con mucho más detalle lo analiza Prieto de la Iglesia (1984b: tomo 1, 317-355).
} 
cas históricas, etc.) y por cómo está entrelazada la narración. Como bien señala Prieto de la Iglesia, su contenido

ofrece sumo interés no sólo por ser una obra desconocida por los historiadores de la Literatura, sino por lo enraizada que está en ella la historia de Segovia — tradiciones, leyendas, fiestas, etc. - y por todo lo que puede aportar a la cultura en general, fundamentalmente en sus vertientes hagiográficas, literarias, de diversiones, etc. (1984a: 24-25).

Pero todo esto no nos debe llamar a engaño, porque el material presentado en los primeros diez capítulos no es más que el marco que prepara la presentación del evento central de la obra: la relación de los sucesos y fiestas con que la ciudad celebró, como anticipamos, la entronización de la imagen de la Virgen en su nuevo santuario. Así, no queda duda alguna respecto del género al que pertenece el texto, que no es otro que el de las populares relaciones de sucesos, tan habituales en la España de los Austrias, sobre todo del siglo $\mathrm{XVII}^{3}$.

\section{DESENTRAÑANDO UN JEROGLÍFICO Y UN ENIGMA}

En este trabajo pretendo pasar revista a algunos de los frutos literarios de los doce certámenes poéticos convocados por el obispo de la ciudad en honor de la Virgen de la Fuencisla, los cuales se describen en detalle en la sección del libro dedicada a la relación de las fiestas celebradas con motivo de la translación de la imagen mariana a su nuevo templo, tal como apunté más arriba. Por haberse celebrado estas fiestas en septiembre, los certámenes coinciden, además, con la octava del Nacimiento de María ${ }^{4}$, lo cual les otorga una especial pertinencia y realce. El propio Jerónimo de Alcalá Yáñez parti-

\footnotetext{
${ }^{3}$ Aunque no es el tema de este trabajo, el género de las relaciones de sucesos ha concitado cada vez mayor interés en el mundo académico, con la consiguiente aportación bibliográfica. Ya en 1903 Jenaro Alenda y Mira le dedicó su copiosa Relaciones de solemnidades y fiestas públicas de España. Para aproximarse hoy al tema pueden verse los trabajos de García Bernal (2006); Bégrand (2006); López Poza (1999) y Pena Sueiro (2001), entre otros. Se han publicado, asimismo, varios trabajos colectivos, entre los que destacan Las relaciones de sucesos en España (1500-1750). Actas del primer coloquio internacional (Alcalá de Henares, 8, 9 y 10 de junio de 1995), editado por María Cruz García de Enterría et al. (1996), y La fiesta. Actas del II Seminario de Relaciones de Sucesos (A Coruña, 1315 de julio de 1998), obra coordinada por Sagrario López Poza y Nieves Pena Sueiro y publicada en 1999. A esto se suma la formación de grupos de investigación sobre el tema en universidades como las de La Coruña, Sevilla y Valencia, entre otras. Por otra parte, existen innumerables trabajos sobre relaciones de sucesos particulares en España y la América virreinal, que no es del caso aquí detallar.

${ }^{4}$ Recordemos que la fiesta de la Natividad de María se celebra cada 8 de septiembre, y los sucesos y fiestas que se relatan ocurrieron entre el 12 y el 23 de septiembre de 1613 .
} 
cipó en varios de estos certámenes con diversas composiciones: tres jeroglíficos, un soneto, unas octavas, varias redondillas y quintillas, unos tercetos y una glosa. Para el cuarto certamen, dedicado a la Anunciación de la Virgen, compuso dos jeroglíficos. Es bien conocida la afición que el humanismo renacentista tenía por los emblemas, jeroglíficos, enigmas, empresas, pegmas, etc., afición que se mantuvo, e incluso aumentó, a lo largo del siglo XVII ${ }^{5}$. De hecho, no es casualidad que esta afición tan acendrada entre los escritores españoles del Siglo de Oro haya corrido parejas con el conceptismo característico del Barroco. Además, y como ocurre especialmente con los emblemas, todas estas imágenes no solo dan cuenta de dicha afición; son muy provechosas desde un punto de vista didáctico y moralizador, ya que la imagen, con su lema y explicación que la acompañan, permite aprehender y entender mejor, a través de la vista, los misterios propios de la fe, tal como ocurre en los casos que analizaremos.

El jeroglífico que paso a revisar, dedicado a la Anunciación, aparece descrito en el texto con las siguientes palabras:

En el uno se pintó una fuente, y a un lado della una arboleda, y entre una espesura un brazo que tañía una vihuela, y apartado de la fuente un unicornio sobre unas altas peñas como que quería bajar a la fuente, la cual tenía encima una letra que decía: Fons aquarum viventium. El unicornio tenía otra letra que decía: Vox tua dulcis et decora facies tua (Canticorum, 14). La letra castellana decía:

Es de gracia su corriente, y aquí, Señora, estáis vos; hoy el unicornio Dios vendrá a cazarse en la fuente (Alcalá Yáñez, 1615: fol. 86r.).

La escena alegórica aquí descrita se materializa en medio de un espacio bucólico que se corresponde con el tópico del locus amoenus (fuente, arboleda, música...). Sobre la fuente figura el lema Fons aquarum viventium, que proviene del pasaje en que el Esposo del Cantar de los Cantares le canta a la Amada: «Fons hortorum, puteus aquarum viventium» ('Eres fuente de jardín, pozo de aguas vivas') $)^{6}$. El unicornio a su vez lleva por lema la frase Vox tua dulcis et decora facies tua, que también proviene del Cantar de los Cantares: «Ostende mihi faciem tuam, / sonet vox tua in auribus meis; / vox enim tua dulcis, et facis tua decora» ('Dame a ver tu rostro, / hazme oír tu voz. I Que tu voz es dulce, / y encantador tu rostro' $)^{7}$. Este unicornio que baja de lo alto (dice el texto que está «sobre unas altas peñas»), es asimilado a Dios en los versos que cierran el jeroglífico, tema que abordaremos más adelante, y se hace presente en la fuente, que es imagen de la Virgen María, quien aparece aquí representada como fuente de aguas vivas, siguiendo una larga

\footnotetext{
${ }^{5}$ Para cuestiones generales de emblemática véanse los trabajos de Praz (1989); Campa (1990); Ledda (1970); Maravall (1990) y Egido (1990). Son también básicos los conocidos libros de Sebastián (1981); Gállego (1991) y Rodríguez de la Flor (1995).

${ }^{6}$ Biblia Vulgata (1999): Cantar de los Cantares 4, 15.

${ }^{7}$ Biblia Vulgata (1999): Cantar de los Cantares 2, 14.
} 
tradición de la devoción mariana, imagen presente ya en las letanías medievales que toman como punto de partida justamente este versículo del Cantar de los Cantares. El motivo también pasó a América, tal como se puede apreciar en el Cancionero mariano de Charcas, cuya canción 117 lleva por título «Al pozo de aguas vivas» (Eichmann, 2009: 454-458) ${ }^{8}$, y en la Letanía Potosina, una de cuyas letanías, elaborada a partir de este mismo verso del Cantar, designa a María como «Puteus aquarum viventium» (Citada por Eichmann, 2009: 185, nota 40). Lo mismo resalta Ramos Gavilán en su relación sobre la Virgen de Copacabana, patrona de Bolivia: «[María] es el estanque donde recogió Dios la gracia para repartirla a su Iglesia»; también dice que es «pozo de aguas vivas» ${ }^{9}$. Ignacio Arellano anota sobre este motivo, en su Diccionario de los autos sacramentales de Calderón, que «la fuente es símbolo universal de vida espiritual y salvación. En la iconografía católica, por ejemplo, es atributo de la Virgen María y se reitera en numerosos contextos con significados varios, pero siempre en este sentido nuclear» (Arellano, 2000: s.v. fuente). Este atributo de María como fuente de las aguas vivas y de gracia queda bien claro con la mención de los dos primeros versos de la redondilla, referidos a María/fuente: «Es de gracia su corriente / y en ella, Señora, estáis vos».

La figura del unicornio, por otra parte, posee una larga tradición en Occidente, en la cual se entrecruzan y mezclan elementos mitológicos y religiosos. Sebastián de Covarrubias acota en su Tesoro (Covarrubias Horozco, 2006), respecto del unicornio, que «hay dél muchos hierolíficos, que por no ser molesto no los refiero aquí» (cosa que lamentamos, porque nos quedamos con las ganas de conocer algunos). En la entrada que le dedica, lo describe como animal que no solo posee la rara virtud de purificar con su cuerno las aguas envenenadas por las serpientes y otros animales ponzoñosos, sino que «el vulgo tiene también recebido dél que si ve una doncella, se le domestica y se recuesta sobre sus faldas y, adormeciéndose en ellas, los cazadores llegan y le prenden, y por esto es símbolo de la castidad». Es lo que se puede apreciar en la ilustración con que Joachim Camerarius (1534-1598) acompaña su Symbolorum et emblematum centuriae quatuor, publicado en Nuremberg en 1605, y que Ignacio Arellano y Rafael Zafra reproducen para la voz unicornio en su reciente edición del Tesoro de Covarrubias (Covarrubias Horozco, 2006):

\footnotetext{
${ }^{8}$ Véase también, en la misma obra, la canción 3, Como entre espinas la rosa, cuyo verso 8 del párrafo 3 reza: «Como fuente de aguas vivas».

${ }^{9}$ A. Ramos Gavilán, Historia del célebre santuario de Nuestra Señora de Copacabana y sus milagros, e invención de la cruz de Carabuco, II, p. 34 y III, Cuarto día, Carta de esclavitud, ambos pasajes citados por Eichmann (2009: 185, n. 40).
} 
"Doncella y unicornio", en Joachim Camerarius, Symbolorum et emblematum centuriae quatuor, Nuremberg, 1605, imagen reproducida en Sebastián de

Covarrubias, Tesoro de la Lengua castellana o española. Todas las ilustraciones que se reproducen en este trabajo pertenecen al dominio público.

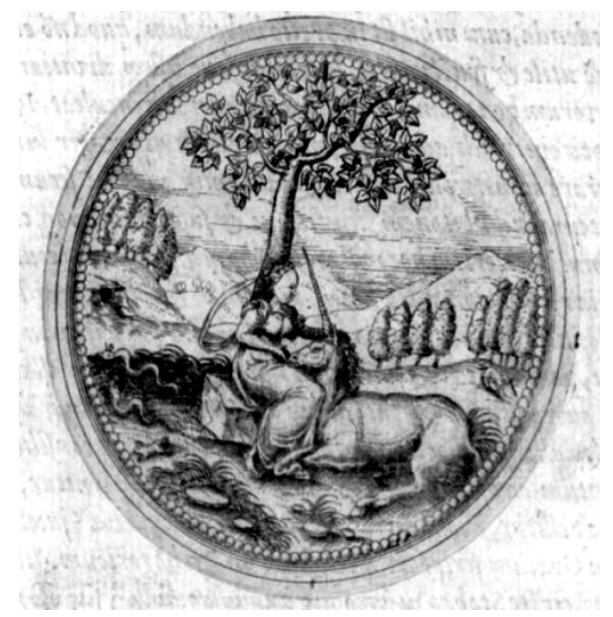

Esta bestia figura también en forma destacada en el Bestiario medieval, donde se lo describe como un animal fiero pero enigmático, y dotado de un cuerno con propiedades milagrosas. Uno de sus atributos es ser capaz de olfatear desde lejos la virginidad, razón por la cual los cazadores suelen ponerle doncellas como cebo para atraparlo:

El unicornio es la bestia más salvaje que existe; nadie se atreve a hacerle frente, debido a un cuerno que tiene en la cabeza. Tan gran placer le produce el olfatear a una doncella y su virginidad que, cuando los cazadores quieren cogerlo, disponen una doncella en su camino; cuando la ve, se duerme en su halda, y ya está atrapado (Bestiario provenzal, citado en Malaxecheverría, 2002: 198).

Otro ejemplo vuelve a insistir sobre el impresionante olfato de este animal:

Monosceros es una bestia que tiene un cuerno en la cabeza; por eso lleva tal nombre. Tiene la traza de un chivo. Es capturado por una doncella, del modo que vais a oír: cuando el hombre quiere cazarlo, apoderarse de él con engaño, se dirige al bosque, donde se encuentra la guarida del animal, y deja allí una doncella con el seno descubierto; el monosceros percibe su olor, se acerca a la virgen, le besa el pecho y se duerme ante ella, buscándose así la muerte. Llega el hombre, que lo mata durante el sueño o se apodera de él vivo para hacer con él lo que quiera (Philippe de Thaün, Le bestiaire, citado en Malaxecheverría, 2002: 195).

Es claro que el poeta pretende resaltar, a través de la imagen del unicornio bajando a la fuente - en un jeroglífico que, recordémoslo, está dedicado a la Anunciación de la Virgen-, la virginidad de María, la mujer pura en que se encarna el Hijo de Dios, aprovechándose del fino olfato que tiene este animal para detectar la virginidad: Dios/unicornio olfatea la virginidad de María/fuente y por eso se encarna en Ella.

En relación con la redondilla — «la letra castellana»- que acompaña al jeroglífico, hay que destacar, en primer lugar, la interesante identificación que 
realiza el autor del unicornio con Dios: el texto dice a la letra, en el verso tres, «hoy el unicornio Dios». También encontramos en el Bestiario medieval esta identificación entre el unicornio y Dios/Cristo, en el contexto de la encarnación del Redentor, tal como podemos apreciar en estos ejemplos:

La bestia de esta índole [el monosceros o unicornio] representa a Jesucristo, que es y será Dios, lo fue y lo seguirá siendo; nació de la Virgen y se encarnó por los hombres, y en pura virginidad, para mostrar su pureza, se apareció a la Virgen y la Virgen lo concibió; es Virgen, lo fue y será, y nunca dejará de serlo. Escuchad brevemente la significación de esto. Esta bestia, en verdad, representa a Dios; la doncella representa, sabedlo, a Santa María (Philippe de Thaün, Le bestiaire, citado en Malaxecheverría, 2002: 195-196).

Vemos así que el unicornio es la figura de nuestro Salvador, el cuerno de salvación alzado para nosotros en la casa de nuestro padre David. Los poderes celestiales no pudieron realizar la obra por sí solos, pero Él tuvo que hacerse carne y morar en el cuerpo de la verdadera Virgen María (Phisiologus, citado en Malaxecheverría, 2002: 194).

Que este animal tenga un solo cuerno en la cabeza representa al Salvador, que dijo: el Padre y yo somos uno solo (De bestiis, citado en Malaxecheverría, 2002: 196).

Hecho este alcance, resta por dilucidar qué significa el verso final de la redondilla: «vendrá a cazarse en la fuente». Ya hemos citado aquí algunos textos del bestiario que se refieren al fino olfato de este animal para detectar a las doncellas. Los versos del jeroglífico compuesto por Alcalá Yáñez apuntan, pues, a esa idea del vulgo recogida por Covarrubias y apuntada ya en numerosos ejemplos tomados del bestiario: el unicornio/Dios baja de las alturas y se deja cazar o atrapar por/en la fuente, que no es otra cosa que el seno virginal de María en el cual se encarnará el Hijo de Dios, tal como el unicornio se recuesta en las faldas de la doncella y, adormecido, se deja atrapar por los cazadores.

Todos los sentidos anotados se refuerzan con un ejemplo tomado de la emblemática, donde también aparece el motivo del unicornio y la doncella. El emblema 1647 recogido por Bernat y Cull en su Enciclopedia de emblemas españoles ilustrados (1999), del cual tomo la imagen que sigue, lleva por título «Unicornio, doncella»:

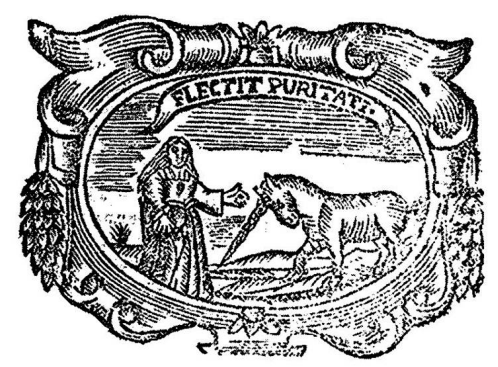

1647. UNICORNIO, DONCELLA
"Unicornio, doncella", en Antonio de Lorea, David pecador, empresas morales, político cristianas, Madrid, Francisco Sanz, 1674. Imagen correspondiente al emblema 1647 de Bernat y Cull, Enciclopedia de emblemas españoles ilustrados. 
Procede de la obra David pecador, empresas morales, político cristianas (Madrid, Francisco Sanz, 1674), de Antonio de Lorea. La imagen muestra un unicornio con el cuerno hacia abajo que se humilla ante una doncella. El lema del emblema es Flectit puritati ('Se rinde a la pureza'), y registra el siguiente comentario:

Entre las fieras cuentan muchos al Unicornio, llamado de algunos Monocerote, nunca visto en España... Hízole el Autor de la naturaleza de grandes privilegios [...]. Visten hermosamente a una doncella, y puesta en parte donde él la vea, se paga tanto de su hermosura que rendido se le pone a los pies, o se acuesta en sus faldas... Bien claro manifiesta la Encarnación del Verbo Eterno en las purísimas entrañas de su Madre (Bernat y Cull, 1999: 794).

Las claves de este emblema son justamente «Encarnación del Verbo en la Virgen María»y «Pureza». Se aprecia, pues, que este emblema se basa en el mismo atributo del unicornio descrito en los bestiarios. Con esto creo que queda resuelto el jeroglífico planteado por el doctor Alcalá, el cual juega con motivos que van desde la mitología y los bestiarios medievales hasta los libros de emblemas, siempre mezclándolos con elementos religiosos y teológicos, como hemos podido apreciar.

El anterior es uno entre varios ejemplos de jeroglíficos con que los poetas participaron en el certamen poético. Otros fueron dedicados a distintos motivos: una nave capitana, la ciudad de Betel, el sol y una rosa de sol, así como un par más a los signos del Zodíaco.

Pero las musas no solo tentaron a los poetas que participaron en el certamen, porque fuera de concurso otros desafíos al ingenio vieron la luz con ocasión de estas fiestas, los cuales fueron también sometidos al escrutinio público. Más adelante en el texto el doctor Alcalá detalla una serie de altares que las distintas órdenes religiosas levantaron por las calles de Segovia en honor de la Virgen, compitiendo entre ellas por cuál altar tenía el mayor adorno y riqueza en su confección. En el caso del altar de la Compañía de Jesús, levantado por los jesuitas frente a la casa del propio Jerónimo de Alcalá, nuestro autor cuenta que él mismo fijó en las ricas telas que lo rodeaban tres enigmas, según propia confesión, «para que los buenos ingenios tuviesen en qué ejercitarse [...], señalando para ellas premios que no duraron mucho sin declarallas, porque aunque es verdad que tenían alguna dificultad, no fue tanta que bastase a hacer resistencia a los grandes supuestos [personas importantes] que dentro y fuera de nuestra ciudad se encierran» (Milagros, fol. 137). Se trata de enigmas cuya respuesta se da en la forma de objetos materiales (una parra, una cebolla) o abstractos (la sombra). Pero la realidad es que tras estos enigmas se esconden desafíos acerca de temas estrictamente teológicos, como veremos a continuación. Paso a centrarme en el segundo de estos enigmas, una composición integrada por una breve introducción y cuatro redondillas de versos octosílabos:

Pintose un cuerpo de una mujer cortada brazos y piernas, corriendo de toda ella sangre, y decía la letra: 
Para que yo valga más
me tratan con tal rigor,
dando el castigo mayor
que el mundo ha visto jamás.

Cabeza y brazos cortó de aqueste cuerpo inocente la inicua y bárbara gente, y cual me veis me dejó.

En tan lastimoso medio, pues que me puedo quejar, por la sangre he de llorar el agua que es mi remedio.

Crecerá mi amargo llanto sin tener más embarazos, hasta que cabeza y brazos venga a cobrar sin espanto.

El texto agrega a continuación la resolución del enigma: «Esta dijo el licenciado Martín Gómez ser la Parra, que en podándola llora, hasta que echa nuevos pámpanos, y así llevó su premio». Es bien conocida la importancia de la imagen de la vid y de los sarmientos en la Biblia. En el Antiguo Testamento la vid es alegoría del pueblo de Israel; en el Evangelio de San Juan (15, 1-8), por otra parte, la imagen de la vid y de los sarmientos representa a Cristo (la vid) y la Iglesia, compuesta por sus miembros (los sarmientos). Jesús y quienes están unidos a Él forman el nuevo pueblo de Dios, que es la Iglesia. Para producir fruto hace falta estar unidos a la verdadera vid, que es Cristo. Los sarmientos podados son los miembros apartados de Él, los que no producen fruto. No es extraño, por tanto, que el motivo de la parra o vid cortada/podada tenga una amplia presencia en la tradición emblemática del Renacimiento y del Barroco. Lo encontramos, por ejemplo, en varios emblemas recogidos por Bernat y Cull en su Enciclopedia. Sin duda el caso más interesante es el del emblema 1693, en que bajo el título «Vid podada, azuela» aparece una imagen que muestra una vid podada acompañada de una azuela que reposa en el suelo:

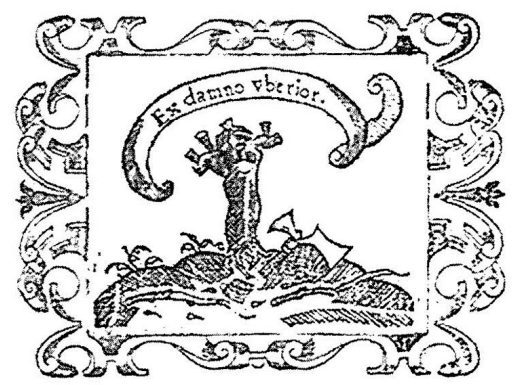

1693. VID PODADA, AZUELA
"Vid podada, azuela", en Juan Francisco de Villava, Empresas espirituales y morales, Baeza, Fernando Díaz de Montoya, 1613. Imagen correspondiente al emblema 1693 de Bernat y Cull, Enciclopedia de emblemas españoles ilustrados. 
El emblema proviene del libro Empresas espirituales y morales de Juan Francisco de Villava (Baeza, Fernando Díaz de Montoya, 1613). Esta obra quizá pudo ser conocida por el doctor Alcalá porque fue publicada el mismo año en que estas fiestas en honor de la Virgen de la Fuencisla tuvieron lugar. El lema reza Ex damno uberior ('Más fértil por el daño recibido'), y la subscriptio de la empresa señala lo siguiente:

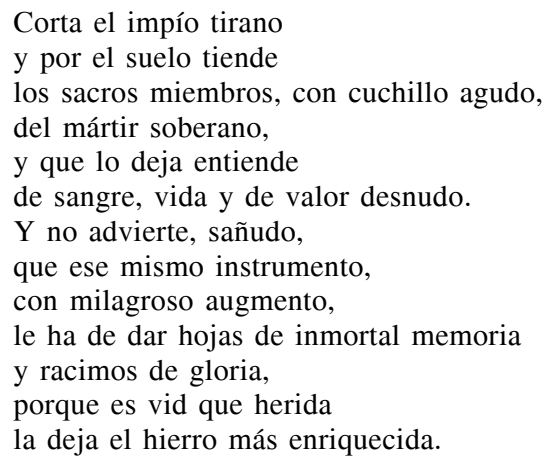

El comentario del emblema explica lo siguiente:

\begin{abstract}
La vid... es símbolo del trabajo, como lo dice Pierio, que por padecer el golpe de la hoz goza de mejorados fructos, y así como no hay árbol que tanto en el invierno encubra la vida como la vid, ansí no hay quien tanto la encubra como el mártir, pero está guardada por ahora con Cristo, y sus méritos en Dios... hasta que venga el verano, que así se llama el tiempo de la universal resurrección, donde parecerá todo lleno de hojas de gloria y de racimos de inmortali$\mathrm{dad}^{10}$.
\end{abstract}

Este emblema, por tanto, representa el martirio (a través de la imagen de la poda) y la gloria de la resurrección consiguiente (el rebrote de la vid), aunque también se puede extender esta representación a la importancia de la ascesis en la vida del cristiano: para dar buen fruto, para lograr la virtud, es necesario desprenderse (ser podado) de los malos hábitos, de los vicios y defectos del hombre. Este es el camino inexcusable, parece sugerir el enigma, en la vida de todo cristiano.

El siguiente emblema, el 1692, procedente de la obra Idea de el buen pastor copiada por los santos doctores, representada en empresas sacras (León, Anisson y Posuel, 1682-1688), del jesuita Francisco Núñez de Cepeda, lleva por título «Vid (Parra), podadera, estacas»:

\footnotetext{
${ }^{10}$ Las citas corresponden a la Primera parte del libro de Villava, empresa 24, Del Mártir, fol. 61r, en Bernat y Cull (1999: 815).
} 
"Vid (Parra), podadera, estacas", en Francisco Núñez de Cepeda, Idea de el buen pastor copiada por los santos doctores, representada en empresas sacras,

León, Anisson y Posuel, 1682-1688. Imagen correspondiente al emblema 1692 de Bernat y Cull, Enciclopedia de emblemas españoles ilustrados.

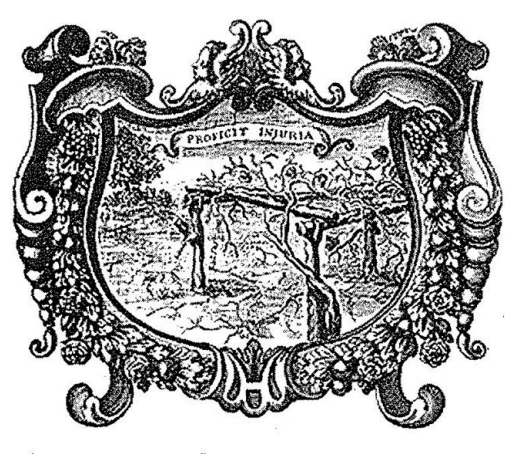

1692. VID [PARRA], PODADERA, ESTACAS

La imagen nos muestra una vid podada que trepa por el emparrado o parón; una podadera cuelga de una estaca y se ven unos sarmientos o cortaduras en el suelo. El lema es Proficit injuria ('La injuria le aprovecha'), y en el comentario respectivo figura lo siguiente:

Cuantos sarmientos corta a la vid el yerro villano, tantos ojos la da, para que desagüe en lágrimas el dolor de las heridas. Quien la viere, como se representa en el cuerpo de esta empresa, despojada de sus frutos... no se persuadirá fácilmente que se puede restituir a su antigua belleza: pero es cierto, que en esos deslucimientos asegura su pompa y en esas pérdidas sus ganancias, pues las que parecen hoy injurias que la ofenden, presto experimentará son beneficios que la mejoran. De el humo de la calumnia sale más resplandeciente y clara la inocencia, y la lima de la mormuración, mordiendo las virtudes, las da nuevo lustre y las perficiona ${ }^{11}$.

El tema alegorizado aquí, a través de la imagen de la vid podada, es el de la fortaleza en la adversidad y la resistencia a la calumnia, como indica el comentario.

Por último, el emblema 1695 lleva por título «Vid, podadera». Proviene de las Empresas morales (Bruselas, Francisco Foppens, 1680) de Juan de Borja:

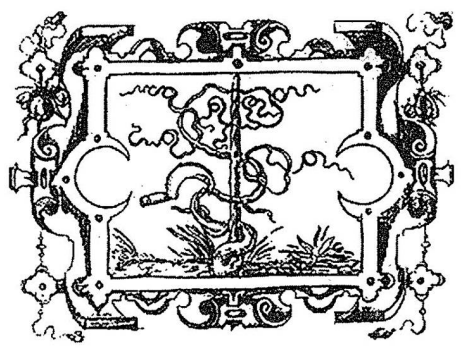

1695. VID, PODADERA
"Vid, podadera", en Juan de Borja, Empresas morales, Bruselas, Francisco Foppens, 1680. Imagen correspondiente al emblema 1695 de Bernat y Cull, Enciclopedia de emblemas españoles ilustrados.

${ }^{11}$ Los fragmentos citados corresponden a la empresa 16 de la obra de Núñez de Cepeda, pp. 265-266, en Bernat y Cull (1999: 815). 
En la imagen del emblema podemos apreciar una vid seca con una podadera. El lema es Sic uberius ('Así dará más fruto'), y el comentario señala lo siguiente:

Que así como para que la vid le dé es menester podarla y aún quitarle parte de los pámpanos, de la misma manera los trabajos y adversidades, como son muertes de los que bien se quieren, pérdidas de lo que mucho se estima, dejar de alcanzar lo que mucho se desea, son como sarmientos secos, y aun pámpanos verdes, que nos desayudan a no dar el fruto que debemos, y así, no se deben sentir, sino pasar con buen ánimo estos trabajos, pues son medios para dar y alcanzar el fruto que más nos conviene ${ }^{12}$.

El tema de este emblema es, evidentemente, la recompensa del sufrimiento en el cielo. En resumen, los tres emblemas revisados toman como motivo la imagen natural de la vid o parra podada, pero lo interesante es que esa misma imagen da pie a distintas claves de interpretación, todas con una dimensión trascendente: por una parte, la imagen de la parra podada y luego brotada sería representación del martirio y la posterior gloria de la resurrección, pero también del esfuerzo ascético por alcanzar la santidad; por otra parte, sería representación de la fortaleza en la adversidad y de la resistencia a la calumnia. Finalmente, podría serlo también del cielo como recompensa de los sufrimientos padecidos en la tierra. Todas estas claves de interpretación nos permiten hacer una lectura más densa del enigma propuesto por el autor, en el cual, como hemos podido ver, se oculta, tras la imagen de una mujer con sus extremidades mutiladas y de cuyas heridas mana profusamente la sangre, no solo una parra, tal como indica el texto como respuesta al enigma, sino algo más: hay un reforzamiento de la imagen evangélica de la vid y de los sarmientos, que es representación, justamente, de la unión de Cristo con su Iglesia. Las extremidades mutiladas de la mujer representan, como los sarmientos podados, la necesidad de eliminar todo lo estéril, poda de la cual la vid (la Iglesia) sale renovada, produciendo nuevos y mejores frutos.

\section{CONCLUSIÓN}

La emblemática fue muy popular en la cultura del Siglo de Oro. La literatura da buena muestra de ello no solo en un nivel estrictamente culto, sino también en las manifestaciones populares, en la forma, por ejemplo, de composiciones literarias que participaban en las celebraciones propias de la devoción mariana, como son justamente las fiestas que se celebraron en Segovia con motivo del traslado de la imagen de la Virgen de la Fuencisla a su nue-

\footnotetext{
${ }^{12}$ La cita es de la Primera parte de la obra de Borja, pp. 128-129, en Bernat y Cull (1999: 816).
} 
vo santuario, suceso descrito en la obra que ha sido objeto de este trabajo. Lo interesante es que en jeroglíficos y enigmas como los que hemos estudiado aquí podemos apreciar cómo la devoción mariana no solo se nutre de la Biblia (imágenes tomadas del Cantar de los Cantares, en el jeroglífico revisado, o de una parábola evangélica, en el caso del enigma), sino también del mundo mitológico, provocando un abrazo entre la mitología y la teología, entre lo pagano y lo divino. Asimismo, podemos apreciar cómo la Iglesia, a lo largo de su historia, frecuentemente se ha servido de variados elementos en su labor de evangelización, siempre con vistas a reforzar las verdades centrales de la fe y la doctrina cristianas. Emblemas, enigmas y jeroglíficos son una excelente forma de apreciar este fenómeno.

\section{BIBLIOGRAFÍA CITADA}

Alcalá Yáñez, Jerónimo de (2005). Alonso, mozo de muchos amos (Primera y Segunda parte). Estudio, edición y notas de Miguel Donoso. Pamplona-Madrid-Frankfurt: Universidad de Navarra-Iberoamericana-Vervuert.

Alcalá Yáñez, Jerónimo de (1615). Milagros de Nuestra Señora de la Fuencisla, grandezas de su nuevo templo, y fiestas que en su translación se hizieron por la ciudad de Segovia, de quien es patrona, año de 1613. Salamanca: Emprenta de Antonia Ramírez viuda.

Alenda y Mira, Jenaro (1903). Relaciones de solemnidades y fiestas públicas de España. Madrid: Sucesores de Rivadeneyra.

Arellano, Ignacio (2000). Diccionario de los autos sacramentales de Calderón. PamplonaKassel: Universidad de Navarra- Reichenberger.

Bégrand, Patrick (ed.) (2006). Las relaciones de sucesos. Relatos fácticos, oficiales y extraordinarios (Encuentro Internacional sobre Relaciones de Sucesos. Besançon, 19-20 de septiembre de 2003). En Annales littéraires de l'université de Franche-Comté, núm. 800. Besançon: Presses Universitaires de Franche-Comté.

Bernat Vistarini, Antonio y Joseph T. Cull (1999). Enciclopedia de emblemas españoles ilustrados. Madrid: AKAL.

Biblia Sacra Iuxta Vulgatam Clementinam (1999). Edición A. Colunga y L. Turrado. Madrid: Biblioteca de Autores Cristianos.

Campa, Pedro F. (1990). Emblemata Hispanica. Durham: Duke University Press.

Covarrubias Horozco, Sebastián de (2006). Tesoro de la lengua castellana o española. Edición integral e ilustrada de I. Arellano y R. Zafra. Pamplona-Madrid-Frankfurt: Universidad de Navarra-Iberoamericana-Vervuert-Real Academia Española-Centro para la Edición de Clásicos Españoles.

Egido, Aurora (1990). «Emblemática y literatura en el Siglo de Oro», Ephialte. 2, pp. 144158.

Eichmann Oerhli, Andrés (2009). Cancionero mariano de Charcas. Pamplona-MadridFrankfurt: Universidad de Navarra-Iberoamericana-Vervuert.

Gállego, Julián (1991). Visión y símbolos en la pintura española del Siglo de Oro. Madrid: Cátedra.

García Bernal, José Jaime (2006). El fasto público en la España de los Austrias. Sevilla: Secretariado de Publicaciones de la Universidad de Sevilla.

García de Enterría, María Cruz et al. (eds.) (1996). Las relaciones de sucesos en España (1500-1750). Actas del Primer Coloquio Internacional (Alcalá de Henares, 8, 9 y 10 de 
junio de 1995). Alcalá de Henares: Servicio de Publicaciones de la Universidad de Alcalá y Publications de la Sorbonne.

Ledda, Gavino (1970). Contributo allo studio della letteratura emblematica in Spagna, 15491613. Pisa: Giardini.

López Poza, Sagrario (1999). «Peculiaridades de las relaciones festivas en forma de libro», en La fiesta. Actas del II Seminario de Relaciones de Sucesos (A Coruña, 13-15 de julio de 1998). Coordinación de Sagrario López Poza y Nieves Pena Sueiro. Ferrol: Sociedad de Cultura Valle Inclán, pp. 213-222.

López Poza, Sagrario y Nieves Pena Sueiro (Coords.) (1999). La fiesta. Actas del II Seminario de Relaciones de Sucesos (A Coruña, 13-15 de julio de 1998). Ferrol: Sociedad de Cultura Valle Inclán.

Malaxecheverría, Ignacio (2002). Bestiario medieval. Madrid: Ediciones Siruela.

Maravall, José Antonio (1990). «La literatura de emblemas en el contexto de la sociedad barroca», en Teatro y literatura en la sociedad barroca. Barcelona: Crítica, pp. 92-118.

Pena Sueiro, Nieves (2001). «Estado de la cuestión sobre el estudio de las Relaciones de sucesos», Pliegos de Bibliofilia. 13.1, 43-66.

Praz, Mario (1989). Imágenes del barroco. Madrid: Ediciones Siruela.

Prieto de la Iglesia, María Remedios (1984a). Alcalá Yáñez y su obra «Milagros de $N{ }^{a}{ }^{a}{ }^{a}$ de la Fuencisla». Segovia: Instituto Diego de Colmenares del C.S.I.C.

Prieto de la Iglesia, María Remedios (1984b). Producción literaria de Alcalá Yáñez, con especial atención a Milagros de la Fuencisla. Ediciones. Tesis doctoral. Madrid: Departamento de Bibliografía, Facultad de Filología, Universidad Complutense de Madrid, 2 tomos.

Rodríguez de la Flor, Fernando (1995). Emblemas. Lecturas de la imagen simbólica. Madrid: Alianza.

Sebastián, Santiago (1981). Contrarreforma y Barroco. Madrid: Alianza.

Fecha de recepción: 12 de septiembre de 2012

Fecha de aceptación: 15 de abril de 2013 